\title{
Cisternal oculomotor schwannoma: a rare cause of anisocoria with ptosis in a child
}

\author{
Vasudev Parashar and Vaibhav Mathur* (D)
}

\begin{abstract}
Background: Primary nerve sheath tumor of cranial nerve is a rare intracranial space occupying lesion that most commonly involves vestibular nerve. Oculomotor nerve schwannoma, without neurofibromatosis, is an extremely uncommon entity especially in children. Though any cranial nerve can be involved by schwannoma except I and II nerve as these cranial nerves lack a Schwann cell sheath.
\end{abstract}

Case presentation: We herein report a 14-year-old boy presenting with an oculomotor schwannoma in the absence of features of neurofibromatosis, manifesting as progressive diplopia, ptosis, and blurring of vision.

Conclusions: Most similar previous case reports in literature reported oculomotor schwannoma in adults, unlike our case. The detection rate of such rare lesions has, however, increased in the last two decades due to neuroimaging advances.

Keywords: Oculomotor schwannoma, Ptosis, Anisocoria, Pediatric, MRI

\section{Introduction}

The incidence of intracranial schwannomas in medical literature is around $6-8 \%$ and most $(90 \%)$ of them show affliction for vestibular nerve followed by the trigeminal nerve, facial nerve, lower cranial nerves and very rarely oculomotor nerve [1-4]. The first case of oculomotor nerve schwannoma was reported by Kovacs in an autopsy in 1927. Thereafter, around 40 cases of oculomotor nerve schwannomas have been described [5-8]. Pediatric intracranial schwannoma originating from the oculomotor nerve is rarely described, and only 12 such cases without coexisting neurofibromatosis in children under 18 years of age have been reported [9-11]. The oculomotor nerve not only carries somatic motor fibers to most extraocular muscles but also contain parasympathetic fibers to the pupillary muscles. Thus, third nerve palsy significantly impairs the patient's quality of life $[5,9]$.

*Correspondence: drmathurvbhv@gmail.com

Department of Neurology, SMS Medical College, Jaipur, Rajasthan, India

\section{Case report}

A 14-year-old male presented in the neurology clinic of our institution with complaints of gradually progressive drooping of the right upper eyelid, diplopia, and blurred vision, without any prior history of headache, fever, altered sensorium, diurnal variation in ptosis, or fatigability. Neurological examination revealed complete ptosis of the right eye, afferent pupillary defect and decreased visual acuity in the right eye with preserved abduction movement. The right pupil was poorly reactive to direct and consensual light and anisocoria was present. Right pupil was $6 \mathrm{~mm}$ in size, while the left pupil was $3 \mathrm{~mm}$ (Fig. 1). There was no chemosis, ocular injection, or painful eye movement. The fundus showed normal appearance of the optic disc in both eyes. There was no evidence of neurofibromatosis in the form of cafe-au-lait spots or neurofibroma under the skin. The other eye was normal, and cognition was appropriate for his age. Ice pack test was negative. Thyroid function tests and routine blood work were normal and anti-acetylcholine receptor antibodies were found negative. Contrast-enhanced MRI Brain (Fig. 2) showed an extra-axial mass along the course of third nerve in suprasellar cistern extending 


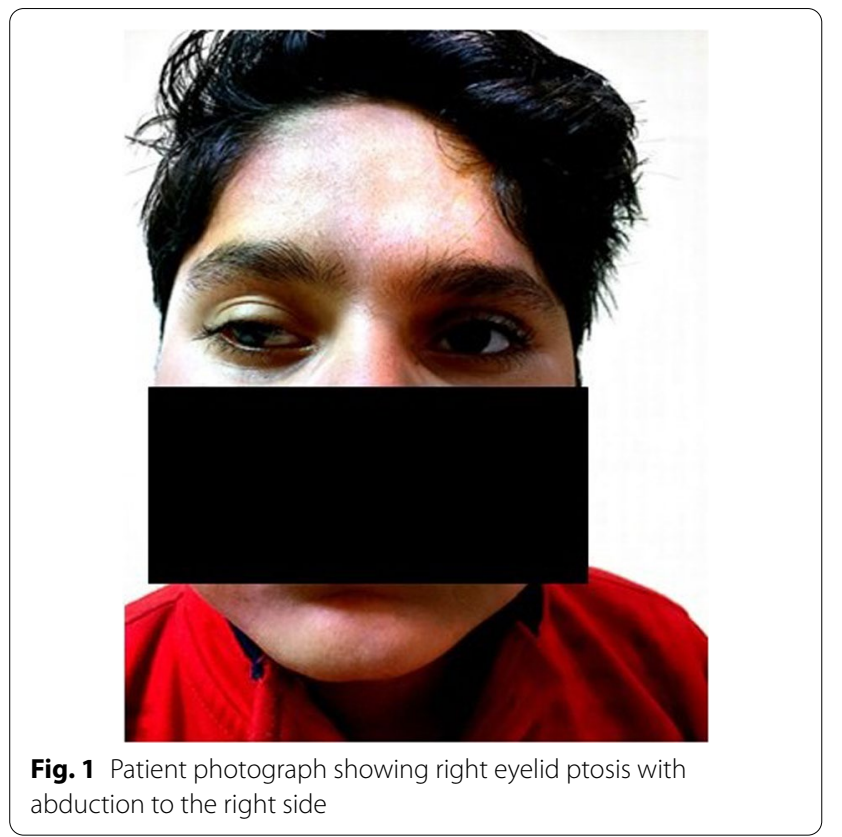

anteriorly along superior aspect of right cavernous sinus superolateral to the internal carotid artery. The size of lesion was $12 \times 13 \mathrm{~mm} \times 6.5 \mathrm{~mm}$, isointense to gray matter on T1- and T2-weighted images (Fig. 1) with dense homogenous post contrast enhancement. An angiogram of brain vessels was normal. Child's mother denied for surgery, and he was followed annually with MRI imaging to see the status of the lesion. He was given a trial of corticosteroids which did not show any significant improvement in his clinical status. On follow-up neuroimaging, the size of lesion reduced marginally over the course of last 2 months. Clinically, exotropia with the limitation of ocular movement persisted.

\section{Discussion}

The preoperative diagnosis of schwannoma is based on clinical features and imaging evaluation that correlate with the distribution of the involved nerve. In our case, the mass was solid and nodular showing isointense signal on $\mathrm{T} 1$ and isointense to hyperintense signals on T2-weighted images. Besides, the location of the lesion is within the nerve pathway and the size of the mass was static over time when compared with follow up MRIs. These characteristics of the mass on MRI are compatible with an oculomotor nerve schwannoma (Table 1). Oculomotor schwannomas are small nodular lesions, usually less than $1 \mathrm{~cm}$ in size and most often located in the interpeduncular cistern or the cavernous sinus. Therefore, careful imaging evaluation is essential to avoid missing lesions. High-resolution MRI or thin-section cranial MRI can be helpful in

Table 1 Radiological findings in oculomotor schwannoma

\section{MRI Characteristics of3rd nerve Schwannoma}

\footnotetext{
1. Nodular lesion usually less than $1 \mathrm{~cm}$ in size

2. Present in the course of the 3rd nerve either cisternal or intraorbital segment

3. T1WI Isointense to gray matter

4. $\mathrm{T} 2 \mathrm{WI}$ Isointense to hyperintense

5. Homogenous enhancement on contrast injection

6. Size remain Static in due course of time on follow up MRI
}

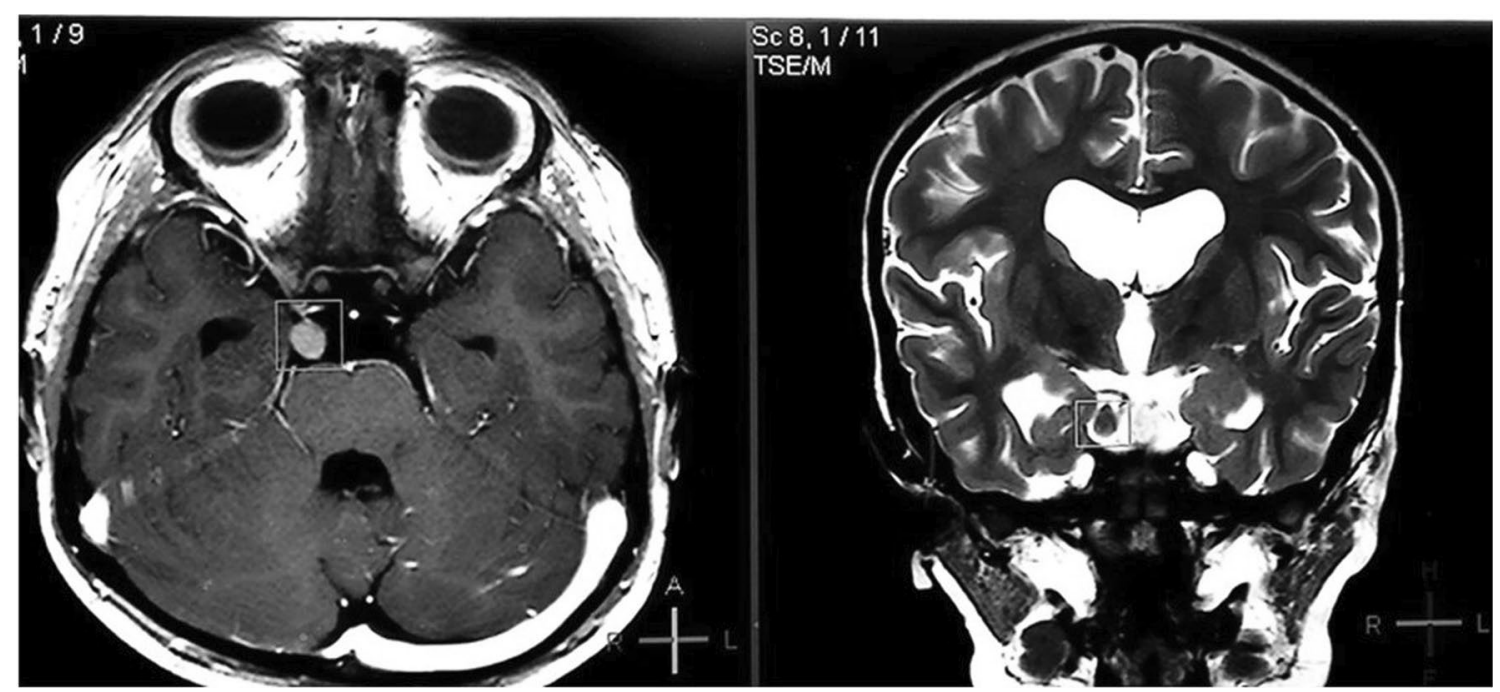

Fig. 2 MRI brain images showing soft tissue intensity appearing nearly iso-intense to gray matter on T1- and T2 weighted images with dense homogenous post contrast enhancement without peri-focal edema of right oculomotor nerve 
Table 2 How to treat oculomotor schwannoma

\begin{tabular}{l}
\hline Treatment options \\
\hline 1. Wait and Watch Policy \\
2. Strict follow up with MRI Brain annually \\
3. Gamma-Knife Radiosurgery \\
4. Radical resection in large, complicated cases (Rarely required)
\end{tabular}

such conditions. Special sequences such as Fast Imaging Employing Steady-state Acquisition (FIESTA), constructive interference in steady-state (CISS), and SPACE are sometimes needed for making a definitive diagnosis of cranial nerve schwannoma on MRI [5, 12-15].

These lesions remain stable over time and observation with follow-up MRI is the only strategy that is required except in large lesions where it may require surgery and radiotherapy. It is difficult to decide the best treatment strategy for oculomotor schwannomas, and depends on case-to-case basis, while many approaches have been described. Katoh et al. recommend 'wait-andsee' policy for asymptomatic patients with oculomotor schwannoma [13]. Kim et al. suggested Gamma Knife radiosurgery as an effective and minimally invasive treatment option for patients with schwannomas originating from the 3rd nerve and it carries minimal risk of postoperative cranial nerve palsy [16]. Radical resection is associated with the worsened oculomotor function, almost invariably results in complete palsy (Table 2).

\section{Conclusions}

Oculomotor schwannoma should be considered in the differential diagnosis of anisocoria with ptosis with a relative afferent pupillary defect in pediatric patients. It needs careful evaluation of imaging finding to diagnose schwannoma as these lesions are small, and deeply located in the brain and very rare in the pediatric age group without neurofibromatosis.

\section{Abbreviations \\ MRI: Magnetic resonance imaging; FIESTA: Fast imaging employing steady- state acquisition; CISS: Constructive interference in steady-state; SPACE: Sampling perfection with application-optimized contrasts by using flip angle evolution.}

\section{Acknowledgements}

We wish to acknowledge our department and colleagues, our families and our patients for their respective vital roles.

\section{Authors' contributions}

VP was the primary treating neurophysician, who diagnosed the patient and suggested publication. VM was his subordinate and assisted in all diagnostic and therapeutic steps. VM was the manuscript writer and VP supervised. Both the authors read and approved the final manuscript.

\section{Funding}

No funding sources.

Availability of data and materials

Complete MRI images available on request to corresponding author.

\section{Declarations}

Ethics approval and consent to participate

We certify that we have obtained institution ethics approval and all appropriate patient consent forms. In our case, the guardian had given their consent for his images and other clinical information to be reported in the journal. The patients/guardian understand that his name and initials will not be published, and due efforts will be made to conceal his identity.

\section{Consent for publication}

Yes, taken.

\section{Competing interests}

The authors declare that they do not have any competing interests.

Received: 19 October 2021 Accepted: 21 December 2021

Published online: 21 February 2022

\section{References}

1. Marutirao R, Singh S, Bhasiora KS, Pandey S, Sardhara J, Das KK, Srivastava AK, Jaiswal S, Behari S. Sporadic cisternal oculomotor nerve schwannoma: a rare case with review of literature. Asian J Neurosurg. 2018;13(4):1269-72.

2. Deora H, Srinivas D, Beniwal M, Vikas V, Rao NK, Somanna S. Rare cranial nerve schwannomas: a retrospective review of nontrigeminal, nonvestibular cranial nerve schwannomas. J Neurosci Rural Pract. 2018;9(2):258-63.

3. Ramey WL, Arnold SJ, Chiu A, Lemole M. A rare case of optic nerve schwannoma: case report and review of the literature. Cureus. 2015;7(4): e265.

4. Cho YH, Sung KS, Song YJ, Kim DC, Choi S, Kim KU. Oculomotor nerve schwannoma: a case report. Brain Tumor Res Treat. 2014;2(1):43-7.

5. Saetia K, Larbcharoensub N, Wetchagama N. Oculomotor nerve schwannoma: a case report and review of the literature. J Med Assoc Thailand = Chotmaihet Thangphaet. 2011;94(8):1002-7.

6. Netuka D, Benes V. Oculomotor nerve schwannoma. Br J Neurosurg. 2003;17(2):168-73.

7. Kumar LP, Monica I, Uppin MS, Kotiyala VJ. Large oculomotor nerve schwannoma-rare entity: a case report with review of literature. J Cancer Res Ther. 2014;10(4):1098-100.

8. lijima K, Tosaka M, Nagano T, Yaoita H, Matsumura N, Nakazato Y, Yoshimoto Y. Oculomotor nerve schwannoma associated with acute hydrocephalus: case report. Neurol Med Chir (Tokyo). 2014;54(8):654-8.

9. Yang SS, Li ZJ, Liu X, Li Y, Li SF, Zhang HD. Pediatric isolated oculomotor nerve schwannoma: a new case report and literature review. Pediatr Neurol. 2013;48(4):321-4. https://doi.org/10.1016/j.pediatrneurol.2012.12. 012.

10. Nagashima H, Yamamoto K, Kawamura A, Nagashima T, Nomura K, Yoshida M. Pediatric orbital schwannoma originating from the oculomotor nerve. J Neurosurg Pediatr. 2012;9(2):165-8.

11. Shamim MS, Bari ME, Chisti KN, Abbas A. A child with intra-orbital oculomotor nerve schwannoma without neurofibromatosis. Can J Neurol Sci. 2008;35(4):528-30.

12. Lingawi SS. Oculomotor nerve schwannoma: MRI appearance. Clin Imaging. 2000;24(2):86-8.

13. Katoh M, Kawamoto T, Ohnishi K, Sawamura Y, Abe H. Asymptomatic schwannoma of the oculomotor nerve: case report. J Clin Neurosci. 2000;7(5):458-60 
14. Skolnik AD, Loevner LA, Sampathu DM, Newman JG, Lee JY, Bagley LJ, Learned KO. Cranial nerve schwannomas: diagnostic imaging approach. Radiographics. 2016;36(5):1463-77.

15. Everton KL, Rassner UA, Osborn AG, Harnsberger HR. The oculomotor cistern: anatomy and high-resolution imaging. AJNR Am J Neuroradiol. 2008;29(7):1344-8.

16. Kim IY, Kondziolka D, Niranjan A, Flickinger JC, Lunsford LD. Gamma Knife surgery for schwannomas originating from cranial nerves III, IV, and VI. J Neurosurg. 2008;109(Suppl):149-53.

\section{Publisher's Note}

Springer Nature remains neutral with regard to jurisdictional claims in published maps and institutional affiliations.

\section{Submit your manuscript to a SpringerOpen ${ }^{\circ}$ journal and benefit from:}

- Convenient online submission

- Rigorous peer review

- Open access: articles freely available online

- High visibility within the field

- Retaining the copyright to your article

Submit your next manuscript at $\boldsymbol{\nabla}$ springeropen.com 